\title{
Determination of Material Properties of Laminates of 15T and T3 Tram Faces
}

Roman Ježdík¹ (ORCID: 0000-0002-6691-0600), Pavel Konopík² (ORCID: 0000-0002-1528-3205), Martin Rund² (ORCID: 0000-0001-8655-5215), Martin Svoboda 3 (ORCID: 0000-0002-7344-1531), Karel Jelen ${ }^{4}$ (ORCID: 00000002-8151-9810)

1VÚKV a.s., Bucharova 1314/8, Praha 5 - Stodůlky, E-mail: jezdik@vukv.cz

${ }^{2}$ COMTES FHT a.s., Průmyslová 995, 33441 Dobřany, E-mail: pavel.konopik@comtesfht.cz, martin.rund@comtesfht.cz

${ }^{3}$ Faculty of Mechanical Engineering, J. E. Purkyně University in Ústí nad Labem, Pasteurova 7, 40096 Ústí nad Labem. E-mail: martin.svoboda@ujep.cz

4FTVS UK, José Mártího 31, Praha 6 - Veleslavín, 220560 225, E-mail: jelen@ftvs.cuni.cz

The article concerns the testing two thin-walled fiberglass materials. The aim of this work was to perform tensile tests at room temperature in order to determine the stress-relative deformation dependence in selected directions and to compare the properties of each individual material in these directions. Characteristics determined in this way are to be used as inputs in simulation models forming a part of the process of validating the dummy model's behaviour in simulations of collisions of the tram front with a pedestrian. Tests have been conducted of such properties of those materials used for external panelling of 15T and T3 tram fronts. The knowledge of these properties is crucial in terms of the mentioned validation. The output of the measurement includes tensile diagrams, including the evaluation of the ultimate tensile strength, elastic modulus and relative elongation at the ultimate tensile strength. Also, the conversion of the elastic modulus for the fibreglass with a different fibre volume part is presented.

Keywords: tensile tests, material, properties, laminate, tram

\section{Introduction}

A composite is generally a material of two or more substances with different properties that together give the final product new properties absent in the original components. [1] Based on the matrix, composites can be further divided into: metal matrix composites (MMCs), ceramic matrix composites (CMCs) and polymer matrix composites (PMCs). According to the secondary phases, composites can be classified into particulate composites, fibrous composites and laminates. [3]

Although humanity has used the properties of composites since time immemorial, the great development and use of composite materials can be dated to the early 1900s and is closely linked to the discovery of plastics. [1]

In recent years, composites have gained prominence in the automotive and aerospace industries due to their excellent material properties, namely high strength, good fatigue resistance, corrosion resistance and low weight especially. All the mentioned properties are critical in the reduction of total weight while maintaining safe operation of the structure. Weight reduction is then reflected in the final fuel consumption. Reducing a car's mass by $100 \mathrm{~kg}$ saves about 0.7 litres of fuel per $100 \mathrm{~km}$ and reduces emissions, which is in accordance with the EU legislation $(95 \mathrm{~g} \mathrm{CO} 2 / \mathrm{km}$ by
2021). [2]

The growing volume of use of the above-mentioned materials entails a growing need for knowledge of their unique properties. Their influence on the accuracy of the resulting analysis is crucial.

\section{Materials and Methods}

In order to provide useful and realistic input data for the finite-element-analyses-based (FEA-based) design a close relationship between the testing laboratory and the simulation team is always necessary. [4] Despite the existence of many standards for individual tests, the size, shape of specimens and method of production vary with high frequency.

Kopula in his work [5] presents a study of the mechanical properties of fibreglass reinforced composite using the Charpy impact test $(\mathrm{L}=55 \mathrm{~mm}$ and $\mathrm{W}=10 \mathrm{~mm}$ without notch) and typical rectangular tensile test specimens (strips) with dimensions of $\mathrm{L}=250 \mathrm{~mm}$ and $\mathrm{W}=25 \mathrm{~mm}$. The thickness of the studied fibre-glass composite was $3.1 \mathrm{~mm}$. Torshizi suggested similar tensile test geometry with dimensions of $175 \mathrm{~mm} \times 25 \mathrm{~mm} \times 3 \mathrm{~mm}$ for a specimen in his paper too. [6]

Unlike Kopula [5], Tamilarsan [7] used an standard dog-bone specimen while studying a carbon-fibre reinforced aluminium sandwich also with a tensile test. Simultaneously, the dynamic Charpy impact test on 
unnotched specimens was conducted.

Hamed used a combination of the above-mentioned geometries. [9] For characterisation of the matrix material properties a dog-bone geometry was used. For fibre/epoxy composites, a strip with dimensions of $200 \mathrm{~mm} \times 25(15) \mathrm{mm} \times 2 \mathrm{~mm}$ was used.

Another view on material characterisation and verification is presented by Yazdani. [10] In 2013, he investigated circular and elliptical cutouts on rectangular plates $(104 \times 100 \times 1.4 \mathrm{~mm})$ and its influence on stress concentration on fibre metal laminates (FML). Results from digital image correlation and strain gauges were compared to the numerical simulation. To obtain Young's modulus, standard long dog-bone specimens were used.

$\mathrm{Wu}$ [11] researched the material properties of FML using tensile test strips of length $300 \mathrm{~mm}$, but with different widths of $25.4 \mathrm{~mm}, 50.8 \mathrm{~mm}$ and $76.2 \mathrm{~mm}$. Simultaneously, a hole with a diameter-to-width ratio of $0.125 \mathrm{~mm}, 0.25 \mathrm{~mm}$ and $0.5 \mathrm{~mm}$ were machined. It was found that the hole reduces the strength by about $40 \%$. He found a strong correlation of the results to the point-stress-criterion model (PSC).

Another example of the utilisation of a dog-bone specimen but for a compression test was presented by Thomson [12] in 2020. The authors performed a series of static and dynamic longitudinal compression tests on a Split-Hopkinson pressure bar (SHPB). To overcome the issue of centring the specimens, he used inplane dog-bone specimens (a cross section of the specimens was $4 \mathrm{~mm} \times 5 \mathrm{~mm}$ and a parallel length of $8 \mathrm{~mm}$ ) glued in to the screwed metallic caps.

One of the disadvantages of the fibreglass composites is the uneven thickness of the laminates. The above-mentioned authors resolve this issue by using an average thickness or by milling down the laminates to a constant thickness. But in the case of large irregularities in the laminates, this approach can lead to misleading results. In our study, we tried to overcome this occurrence by using tensile test specimens with a reduced parallel specimen length. The final geometry of the specimens is described in next section.

The aim of this work is to determine the stress-relative deformation dependence in the selected directions and to compare the properties of each individual material in these directions. In case it turns out that the properties of each individual material do not differ significantly in individual directions, it will be possible to consider these materials as isotropic. This would simplify the situation, as the determined characteristics will be used as inputs in simulation models that form a part of the process of validating the behaviour of the anthropometric test device (ATD, or a so-called crash test dummy) in simulations of a tram front colliding with a pedestrian, see Fig. 1. Tests have been conducted of these properties of materials, which are ma- inly used for external, more complex surfaces of panelling for the $15 \mathrm{~T}$ and $\mathrm{T} 3$ tram fronts. The knowledge of these properties is indispensable in terms of the mentioned validation.

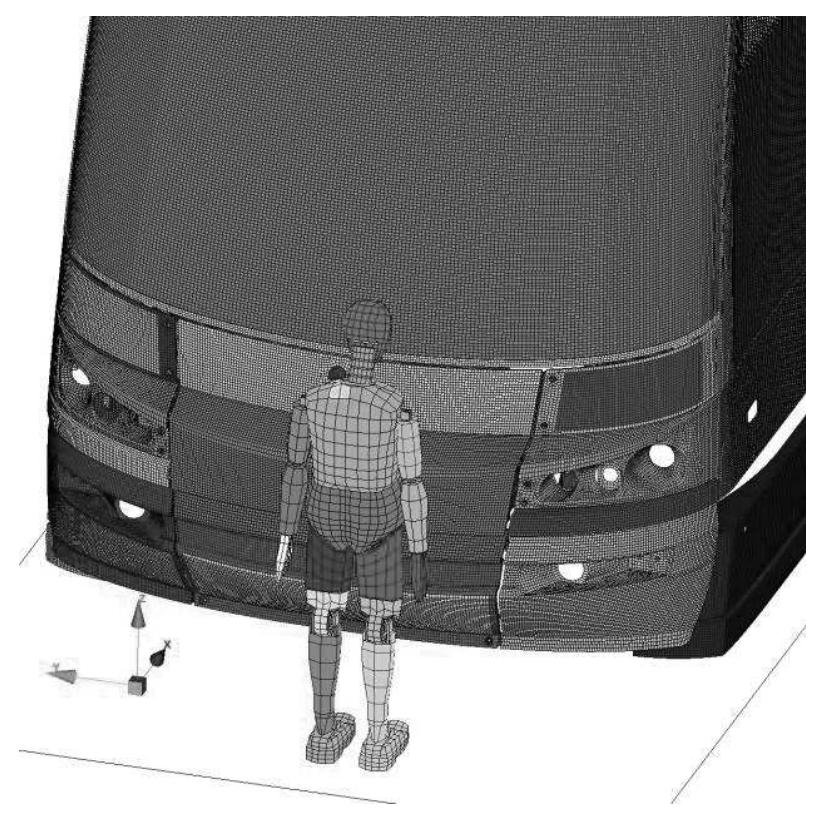

a) $15 \mathrm{~T}$ tram front

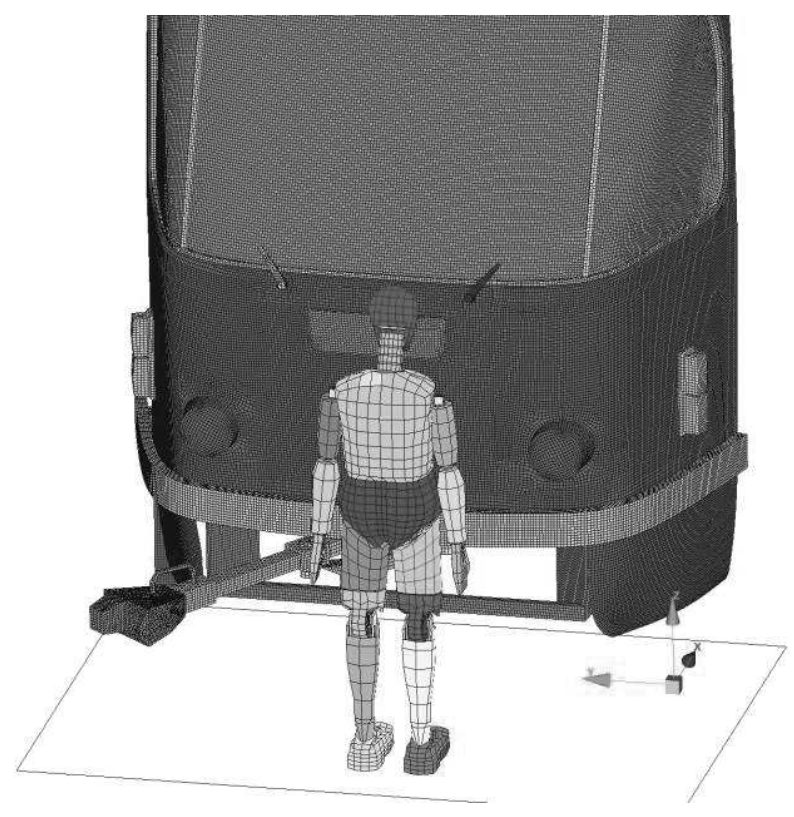

b) T3 tram front

Fig. 1 Simulation models of tram front - pedestrian collision

\section{Test specimens}

The test material for the $15 \mathrm{~T}$ was delivered in the form of strips with the dimensions $26 \mathrm{~mm} \times 250 \mathrm{~mm}$, see Fig. 2a. The supplier has cut the strips in four various orientations, see Fig. 2b. Some strips were defective, and their thickness was not constant as it ranged from $2-3.5 \mathrm{~mm}$. For testing, strips with minimum defects and constant thickness, where possible, were 
chosen. For each orientation, a set of five testing bodies was manufactured with geometry according to Fig. 3a.

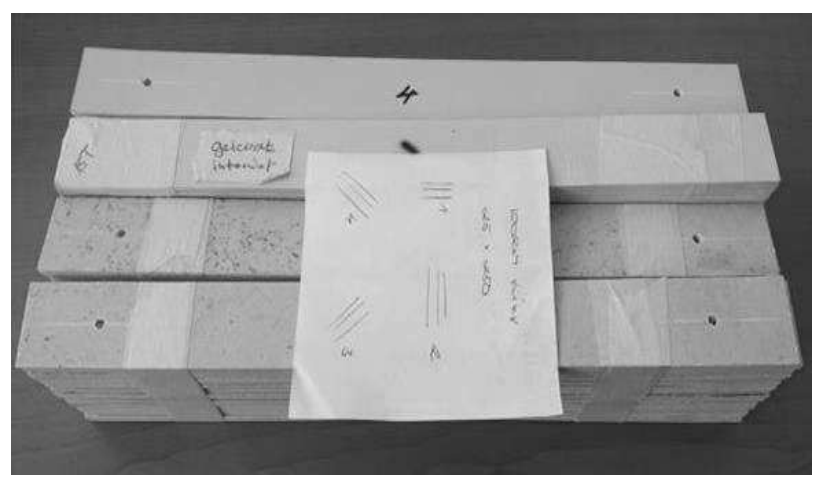

a) Supplied condition - specimens

\section{Direction A}

\section{Direction B}

\section{Direction C}

\section{Direction D}

\section{b) Indication of testing bodies orientation}

Fig. 2 Testing material $15 T$

Testing material of T3 was delivered in the form of a $470 \mathrm{~mm}$ x $655 \mathrm{~mm}$ composite laminate plate, see Fig. 3b. The plate was curved with defects on the surface, and its thickness ranged from $2.5-4.5 \mathrm{~mm}$. Flat testing bodies were cut out from the plate using water cutting with the geometry shown in Fig. 3a. Bodies have been made in four various orientations whereas the set of five bodies has been manufactured for each orientation in the same way as for the $15 \mathrm{~T}$ material, see Fig. 2b or Fig. 3c. The section plan was designed so that the test specimens were placed outside the aforementioned defects in the plate.

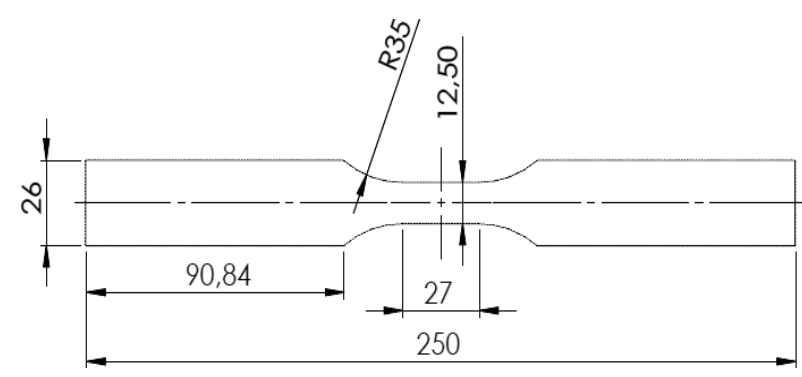

a) Geometry of the testing body for the tensile test

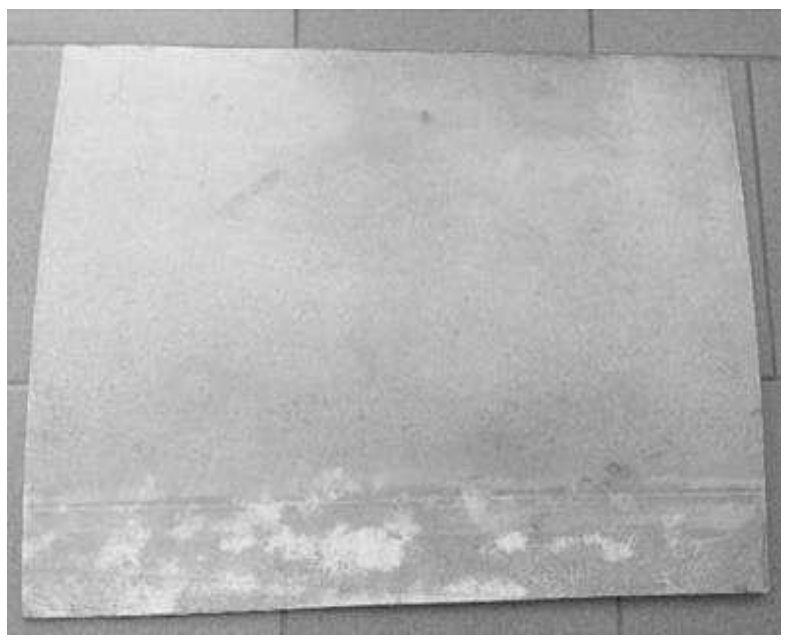

b) Semi-product

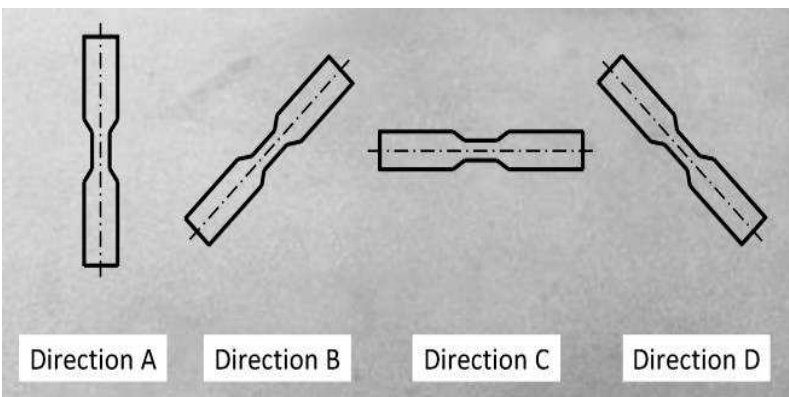

c) Specimen orientation

Fig. 3 Testing material T3

\section{Tensile tests at a temperature of $23^{\circ} \mathrm{C}$}

For testing, the Zwick-Roell 250 servo-electric tensile testing machine was used, see Fig. 5. The elongation of the testing bodies was measured with a mechanical strain gauge made by MTS. For the best possible comparability of individual measurements, all tests have been performed on the same machine and using the same strain gauge. Prior to testing, the width and thickness of all testing bodies were measured. The test bodies were clamped to the machine with flat hydraulic jaws. Tensile tests were performed at a constant crossbar displacement speed of $0.5 \mathrm{~mm} \cdot \mathrm{min}^{-1}$. Testing bodies have been indicated according to Fig. 4 and Tab. 1. 


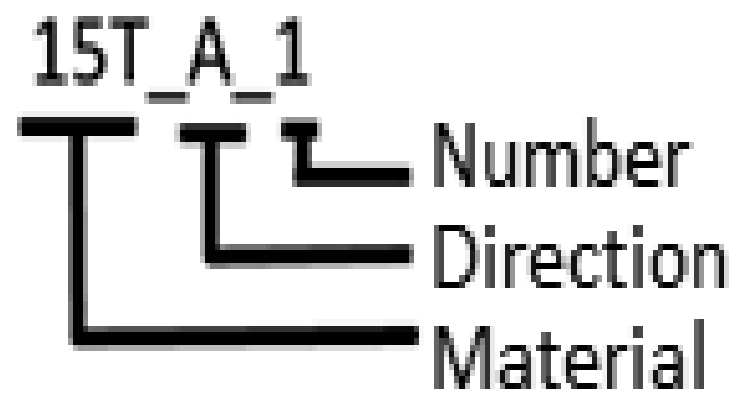

Fig. 4 Indication of testing bodies

Tab. 1 List of testing bodies

\begin{tabular}{|c|c|c|}
\hline Set of specimens & Orientation & $\begin{array}{c}\text { Number of } \\
\text { pieces }\end{array}$ \\
\hline $15 \mathrm{~T}_{-} \mathrm{A}$ & $\mathrm{A}|| \mid$ & 5 \\
\hline 15T_B & $\mathrm{B} / / /$ & 5 \\
\hline 15T_C & $C \equiv$ & 5 \\
\hline 15T_D & $\mathrm{D} \backslash \backslash \backslash$ & 5 \\
\hline T3_A & $\mathrm{A}|| \mid$ & 5 \\
\hline T3_B & $\mathrm{B} / / /$ & 5 \\
\hline T3_C & $C \equiv$ & 5 \\
\hline T3_D & $\mathrm{D} \backslash \backslash \backslash$ & 5 \\
\hline \multicolumn{2}{|c|}{ total } & 40 \\
\hline
\end{tabular}

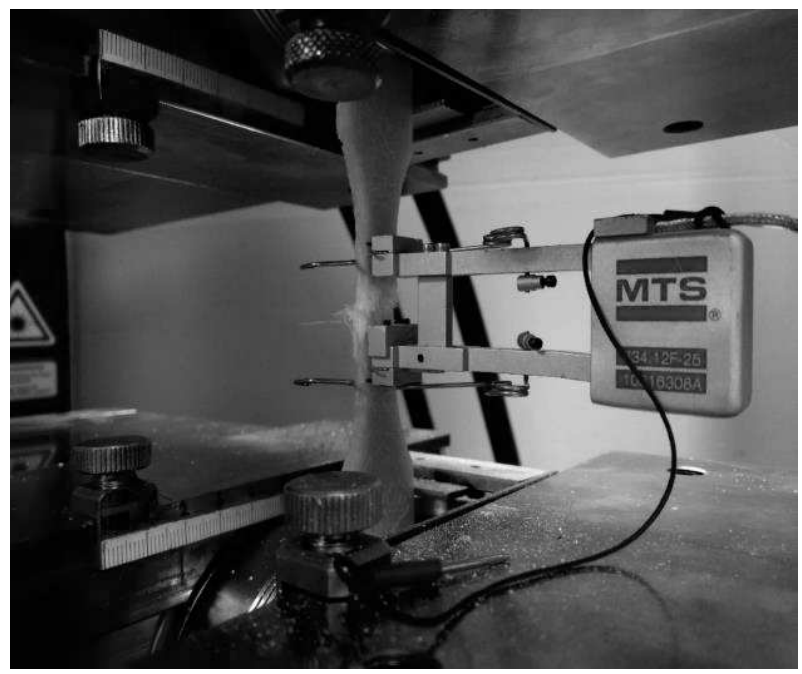

Fig. 5 Testing equipment Zwick - Roell 250

\section{Test results}

The measured data was used for drawing tensile diagrams with the dependence of the loading stress on the magnitude of the relative elongation of the testing body measured by the strain gauge. For each testing body, the value of the ultimate tensile strength $R m$, the value of the relative elongation to the ultimate tensile strength $\varepsilon \mathrm{m}$ and the value of the elastic modulus $E$ were evaluated from the tensile diagram. The elastic modulus was evaluated according to the standard EN ISO 527-1 [8] as the slope of the tensile diagram curve (stress/relative elongation) in the interval of relative elongation between $\varepsilon_{1}=0.05 \%$ a $\varepsilon_{2}=0.25 \%$, see Fig. 6. The relative elongation value $\varepsilon_{\mathrm{m}}$ was determined as the actual magnitude of the elongation in $\%$, measured by a strain gauge at the point of achieving the maximum tension that the testing body withstood, see Fig. 7.

For evaluated values from the tension diagrams, see tables Tab. 2 and Tab. 3. For tension diagrams, see Fig. 8 for the 15T material and Fig. 9 for T3. For easier result comparison, the values of the sets of five were averaged, see Tab. 4. With the 15T_A1 testing body, a preliminary failure occurred due to the defect, and this test has been considered invalid.

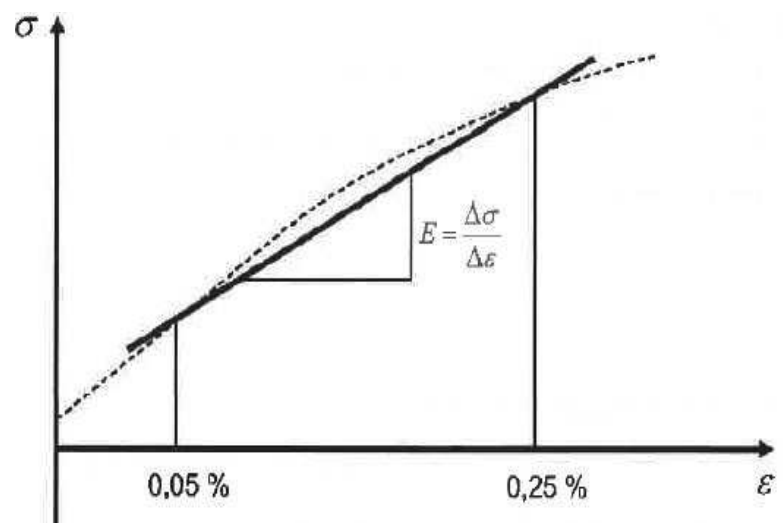

Fig. 6 Example of determining the elasticity module of composite materials according to CSN EN ISO 527-1

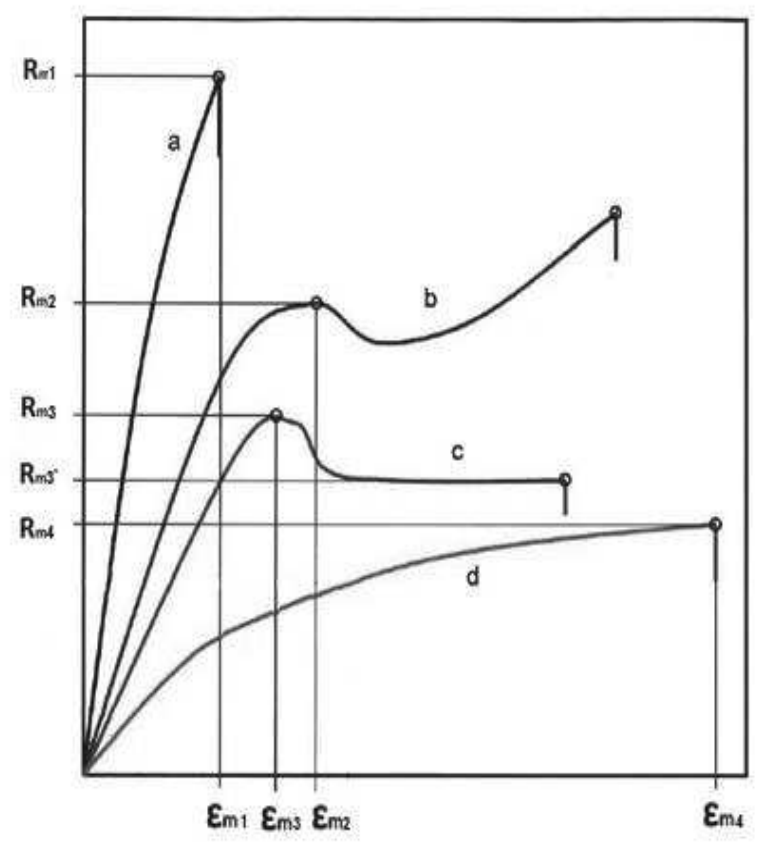

Fig. 7 Example of determining the relative elongation to the ultimate tensile strength according to CSN EN ISO 527-1 
Tab. 2 Results of tensile tests for the 15 T material

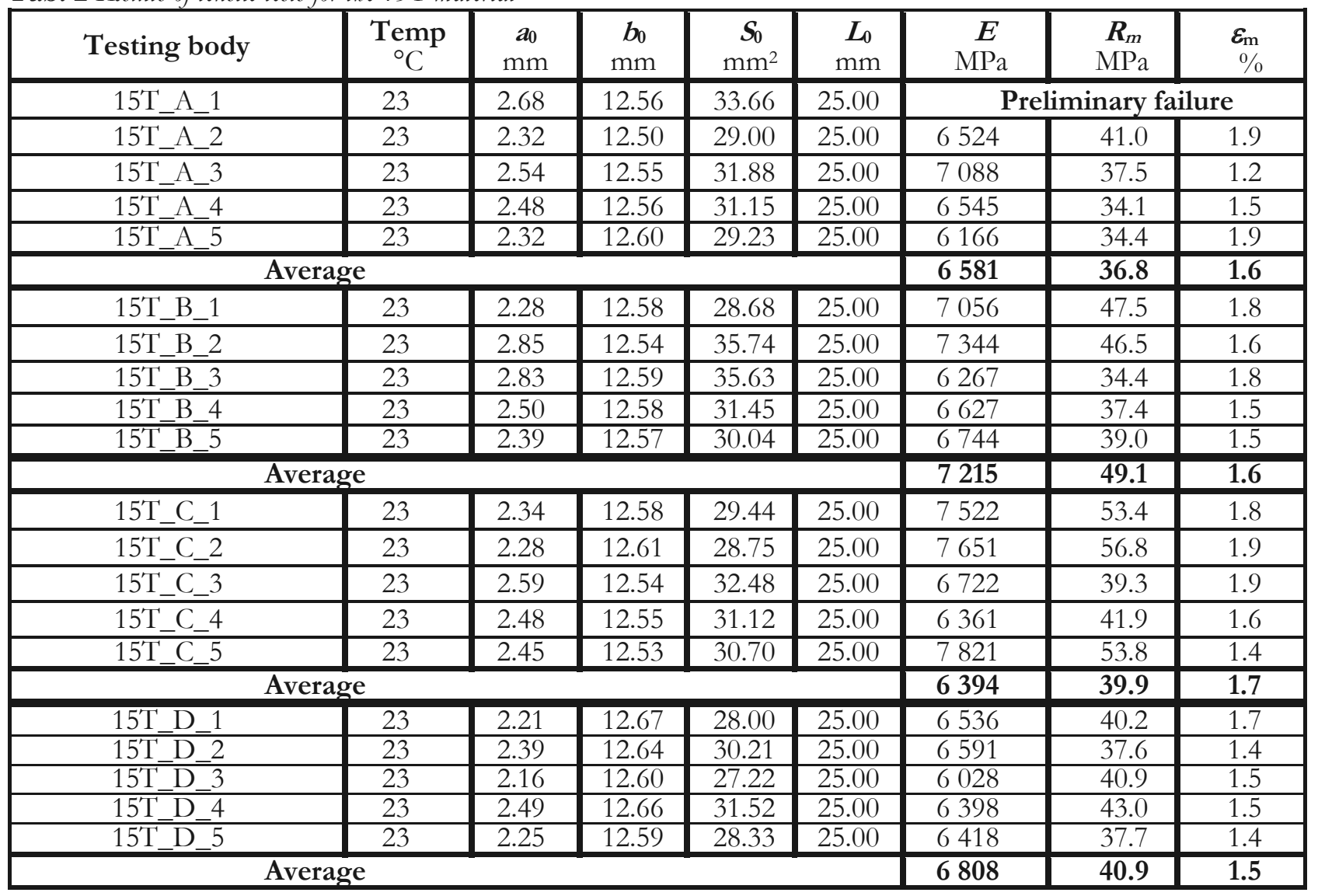

Tab. 3 Results of tensile tests for the T3 material

\begin{tabular}{|c|c|c|c|c|c|c|c|c|}
\hline Testing body & $\underset{{ }^{\circ} \mathrm{C}}{\text { Temp }}$ & $\begin{array}{c}\boldsymbol{a}_{0} \\
\mathrm{~mm}\end{array}$ & $\begin{array}{c}\boldsymbol{b}_{0} \\
\mathrm{~mm}\end{array}$ & $\begin{array}{c}\boldsymbol{S}_{0} \\
\mathrm{~mm}^{2}\end{array}$ & $\begin{array}{c}\boldsymbol{L}_{0} \\
\mathrm{~mm}\end{array}$ & $\begin{array}{c}\boldsymbol{E} \\
\mathrm{MPa}\end{array}$ & $\begin{array}{c}\boldsymbol{R}_{\boldsymbol{m}} \\
\mathrm{MPa}\end{array}$ & $\begin{array}{r}\boldsymbol{\varepsilon}_{\mathrm{m}} \\
\%\end{array}$ \\
\hline T3_A_1 & 23 & 3.33 & 12.35 & 41.13 & 25.00 & 10110 & 144.7 & 2.2 \\
\hline T3_A_2 & 23 & 3.50 & 12.36 & 43.26 & 25.00 & 10258 & 137.4 & 2.1 \\
\hline T3_A_3 & 23 & 3.73 & 12.33 & 45.99 & 25.00 & 10220 & 128.4 & 1.8 \\
\hline T3_A_4 & 23 & 3.71 & 12.31 & 45.67 & 25.00 & 9570 & 131.9 & 2.0 \\
\hline T3_A_5 & 23 & 3.64 & 12.30 & 44.77 & 25.00 & 9395 & 134.4 & 2.2 \\
\hline \multicolumn{6}{|c|}{ Average } & 9911 & 135.4 & 2.1 \\
\hline T3_B_1 & 23 & 4.31 & 12.34 & 53.19 & 25.00 & 8344 & 94.3 & 1.9 \\
\hline T3_B_2 & 23 & 4.45 & 12.41 & 55.22 & 25.00 & 7818 & 99.2 & 1.9 \\
\hline T3_B_3 & 23 & 4.49 & 12.43 & 55.81 & 25.00 & 7365 & 92.0 & 1.9 \\
\hline T3_B_4 & 23 & 4.43 & 12.39 & 54.89 & 25.00 & 7234 & 95.5 & 2.1 \\
\hline T3_B_5 & 23 & 4.35 & 12.36 & 53.77 & 25.00 & 8099 & 100.2 & 1.8 \\
\hline \multicolumn{6}{|c|}{ Average } & 7772 & 96.3 & 1.9 \\
\hline T3_C_1 & 23 & 3.92 & 12.30 & 48.22 & 25.00 & 8502 & 112.6 & 2.1 \\
\hline T3_C_2 & 23 & 4.16 & 12.41 & 51.63 & 25.00 & 8655 & 116.0 & 2.1 \\
\hline T3_C_3 & 23 & 4.43 & 12.40 & 54.93 & 25.00 & 8863 & 103.3 & 2.0 \\
\hline T3_C_4 & 23 & 4.53 & 12.36 & 55.99 & 25.00 & 7829 & 106.6 & 2.1 \\
\hline T3_C_5 & 23 & 4.10 & 12.40 & 50.84 & 25.00 & 8190 & 115.8 & 2.1 \\
\hline \multicolumn{6}{|c|}{ Average } & 8408 & 110.9 & 2.1 \\
\hline T3_D_1 & 23 & 4.23 & 12.34 & 52.20 & 25.00 & 7763 & 98.5 & 1.9 \\
\hline T3_D_2 & 23 & 4.21 & 12.37 & 52.08 & 25.00 & 8288 & 110.9 & 2.1 \\
\hline T3_D_3 & 23 & 4.02 & 12.31 & 49.49 & 25.00 & 8694 & 123.3 & 2.0 \\
\hline T3_D_4 & 23 & 4.81 & 12.11 & 58.25 & 25.00 & 7783 & 90.8 & 1.6 \\
\hline T3_D_5 & 23 & 4.98 & 12.41 & 61.80 & 25.00 & 7971 & 95.5 & 2.4 \\
\hline \multicolumn{6}{|c|}{ Average } & 8100 & 103.8 & 2.0 \\
\hline
\end{tabular}




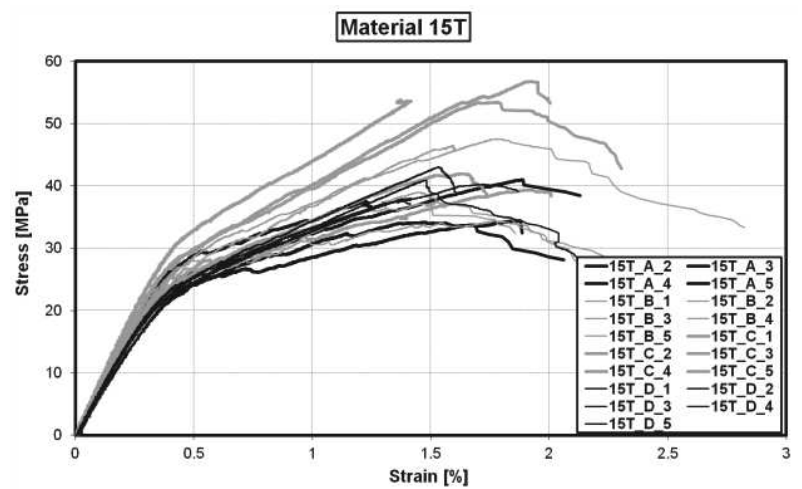

Fig. 8 Tensile diagrams of the 15 T material

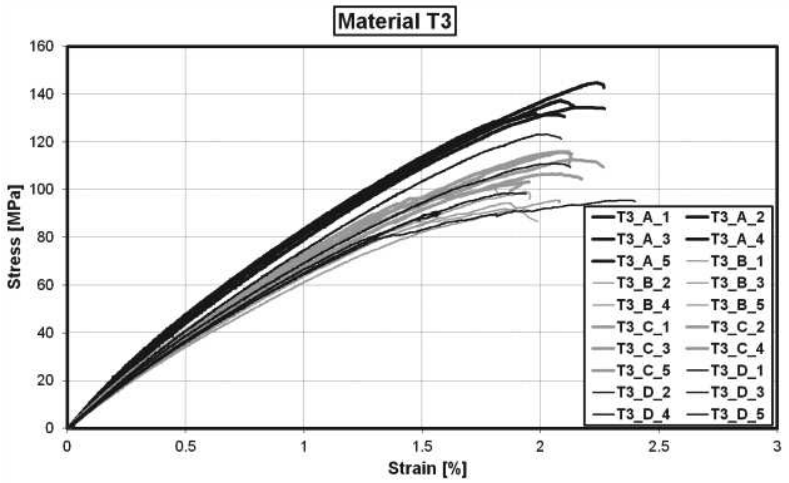

Fig. 9 Tensile diagrams of the T3 material

Tab. 4 Averaged results

\begin{tabular}{|c|c|c|c|c|}
\hline \multicolumn{2}{|c|}{ Testing bodies } & $\begin{array}{c}\mathbf{E} \\
\mathrm{MPa}\end{array}$ & $\begin{array}{l}\mathbf{R m} \\
\mathrm{MPa}\end{array}$ & $\begin{array}{c}\boldsymbol{\varepsilon}_{\mathrm{m}} \\
\%\end{array}$ \\
\hline 15T_A & 111 & 6581 & 36.8 & 1.6 \\
\hline 15T_B & $/ / 1$ & 7215 & 49.1 & 1.6 \\
\hline 15T_C & $\equiv$ & 6394 & 39.9 & 1.7 \\
\hline 15T_D & 111 & 6808 & 40.9 & 1.5 \\
\hline \multicolumn{2}{|c|}{ Average } & 6750 & 41.7 & 1.6 \\
\hline T3_A & 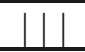 & 9911 & 135.4 & 2.1 \\
\hline T3_B & $1 / 1$ & 7772 & 96.3 & 1.9 \\
\hline T3_C & $\equiv$ & 8408 & 110.9 & 2.1 \\
\hline T3_D & 111 & 8100 & 103.8 & 2.0 \\
\hline \multicolumn{2}{|c|}{ Average } & 8547 & 111.6 & 2.0 \\
\hline
\end{tabular}

The results reported for the $15 \mathrm{~T}$ material correspond to the laminate used as a coating for sandwich roof panels made using the RTM (resin transfer moulding) technology. According to the manufacturer's information, these laminates' share of fibres in terms of volume is app $20 \%$. However, for simulation models, the knowledge of the stiffness of laminates located below the level of the windscreen is required, yet these specimens were not available for testing. It concerns the laminates of the same composition yet produced using the manual laying technology. Using the manufacturer indicated density of the under-window laminate $\rho_{c}=2.0 \mathrm{~g} . \mathrm{cm}^{-3}$ and with the knowledge of approximate values of density of individual laminate components (fibres: $\rho_{f}=2.6 \mathrm{~g} . \mathrm{cm}^{-3}$, matrix $\rho_{m}=1.6 \mathrm{~g} . \mathrm{cm}^{-}$ 3) the fibre volume fraction $V_{f}$ can be determined from the relation (see e. g. [13]):

$$
V_{f}=\frac{\rho_{c}-\rho_{m}}{\rho_{f}-\rho_{m}}
$$

Therefore, the value is $40 \%$. Please note that this is an approximate value because the input values are also approximate and, in addition, cavities occurring in the real laminate were not considered, which according to [13] can amount to $1-5 \%$ depending on the quality.

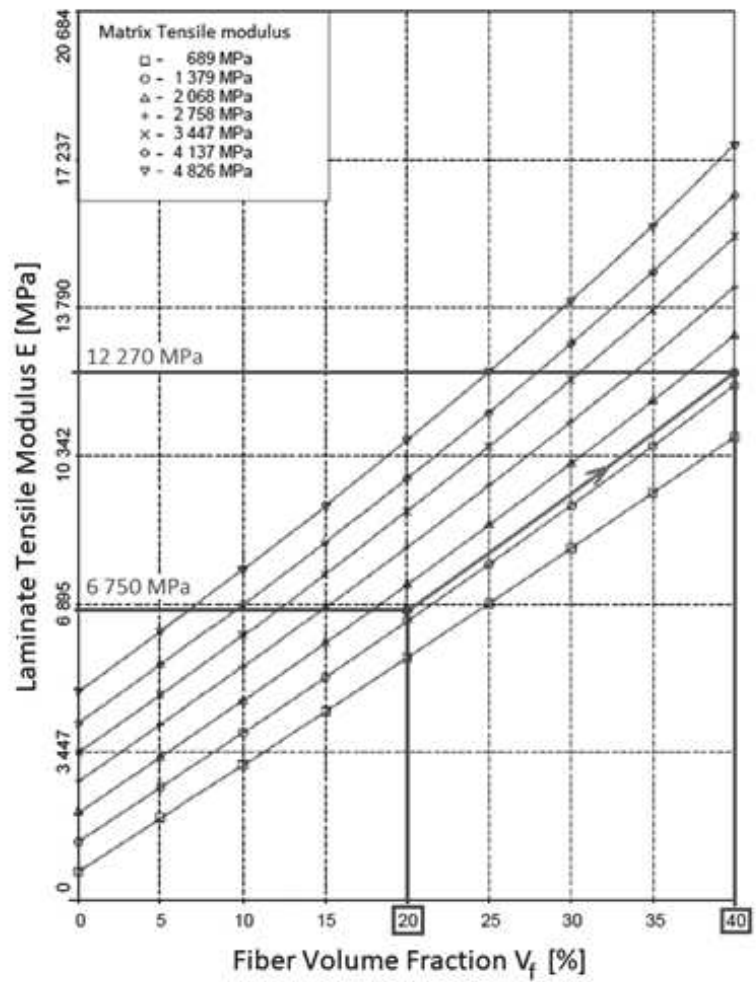

Fig. 10 Conversion of the tension elasticity modulus value taken from [15] and adapted 
On the basis of the above-mentioned volume shares, it is possible to convert the measured average value of the elastic modulus of the roof laminate $(E=$ $6750 \mathrm{MPa}$ ) according to [14] from the graph taken from the research report [15] to the value corresponding to the under-window laminate, which is the input for simulation models. Fig. 10 makes it clear that this value is $12270 \mathrm{MPa}$. In addition, it is obvious from the chart that the value of the elastic modulus of the matrix is around $1600 \mathrm{MPa}$.

\section{Conclusion}

Tests have been carried out on the properties of materials that are used for external panelling of $15 \mathrm{~T}$ and $\mathrm{T} 3 \mathrm{tram}$ fronts. The determined characteristics are to be used as inputs in simulation models forming a part of the process of validating the dummy model behaviour in simulations of collisions of the tram front with a pedestrian.

Tensile tests have been made under the temperature of $23^{\circ} \mathrm{C}$, in the lab with the controlled temperature. The displacement speed of the crossbar of the testing machine was constant $-0.5 \mathrm{~mm} \cdot \mathrm{min}^{-1}$.

For laminates used on the structure of the roof part of the $15 \mathrm{~T}$ tram face, average values of the elastic modulus $6.750 \mathrm{MPa}$ with deviations in individual directions of $+7 \%$ and $-5 \%$, the average tensile strength values of $41.7 \mathrm{MPa}$ with deviations of $+18 \%$ and $-12 \%$ and average tensibility values to the ultimate tensile strength of $1.6 \%$ with deviations of $\pm 6 \%$ were found. The value of the elastic modulus of the window laminates obtained by the conversion is $12.270 \mathrm{MPa}$.

For laminates used on the structure of the T3 tram face, average values of the modulus of elasticity $8547 \mathrm{MPa}$ with deviations in individual directions of $+16 \%$ and $-9 \%$, the average tensile strength values of 111.6 $\mathrm{MPa}$ with deviations of $+21 \%$ and $-14 \%$ and average tensibility values to the ultimate tensile strength of $2.0 \%$ with deviations of $\pm 5 \%$ was found.

Due to the detected deviations of the elastic modulus for individual directions, it can be stated that in cases where there is no material failure, we can neglect the laminate anisotropy for modelling the laminate used for the construction of the $15 \mathrm{~T}$ tram front. In the case of the second tested laminate (T3), deviations are greater, and the anisotropy may well be taken into account here.

\section{Acknowledgment}

The article was created with the contribution by grant UJEP-IGA-TC-2019-48-04-2 and by grant OP VVV CZ.02.1.01/0.0/0.0/16_026/0008401 UK Praha.

Authors of the article 'Possibilities of Using Tram Windscreen Impact Tests in Analysis of HumanMachine Accidents' (December 2019, Vol. 19, No.
6) apologize that the project of the Ministry of Industry and Trade of the Czech Republic TRIO FV20441 'Research and development of Safe Tram Front end' was not published in Acknowledgments. This project supported most of the work presented in this article.

\section{References}

[1] JOHNSON, TODD. "History of Composites." ThoughtCo, Aug. 25, 2020, thoughtco.com/history-of-composites-820404.

[2] MURDLIDHAR, P., et. All (2018). Lightweight Composite Materials for Automotive -A Review, International Research Journal of Engineering and Technology (IRJET), V5 I11, 2018.

[3] JANOVEC, J., et all (2008). Perspektivni materiály, CVUT, 2008

[4] DŽUGAN, J., ŠPANIEL, M., PRANTL, A., KONOPÍK, P., RŮŽIČKA, J., \& KUŽELKA, J. (2018). Identification of ductile damage parameters for pressure vessel steel. Nuclear Engineering and Design, 328, 372-380. doi:10.1016/j.nucengdes.2015.12.014

[5] KOPPUlA S., KVITI, A., NAMALA, K. (2015). Experimental investigation of fibre reinfocedcomposite material under impact load, Materials Research 2015, DOI: http://dx.doi.org/10.1590/1516-1439.017215

[6] TORSHIZI, SEM, DARIUSHI, S., SADIGHI, M. (2010). A study on tensile properties of a novel fiber/metal laminates, Materials Science and Engineering A 527 (2010) 4920-4925, 2010

[7] TAMILARSAN, U. et all (2015). Mechanical Properties Evaluation of the Carbon Fibre Reinforced Aluminium Sandwich Composites, Materials Research. 2015; 18(5): 1029-1037, DOI: http://dx.doi.org/10.1590/1516-1439.017215

[8] EN ISO 527-1 Plastics - Determination of tensile properties - Part 1: General principles, 2019

[9] HAMED, A., F., HAMDAN, M., M., SAHARI, B., B. (2008). Experimental characterization of filament wound Glass/Epoxy and Carbon/Epoxy composite materials, ARPN Journal of Engineering and Applied Science Vol.3, No.4, 2008, ISSN 1819-6608

[10] YAZDANI, S. et all (2013). Experimental and numerical stress analysis of FML plates with cutouts under in-plane loading, MECHANIKA. 2013 Volume 19(2): 128-134, http://dx.doi.org/10.5755/j01.mech.19.2.415 2 
[11] WU, G., TAN, Y., YANG, JM. (2006). Evluation of residual strength of notched fiber metal laminates Materials Science and Engineering A, 2006,

[12] THOMSON, D., QUINO, G., CUI, H. (2020). Strain-rate and off-axis loading effects on the fibre compression strength of CFRP laminates: Experiments and constitutive modelling, Composites Science and Technology, 2020, V195, https://doi.org/10.1016/j.compscitech.2020.108210.

[13] AGARWAL, B. BROUTMAN, L., CHANDRASHEKHARA, K. (2015). Analysis and Performance of Fiber Composites, 3th edition, Sai Printo Pack Pvt. Ltd., Reprint 2015, ISBN 978-81-265-3636-8
[14] ASME RTP-1-2000, Reinforced Thermoset Plastic Reinforced Equipment, New York, NY: ASME International, 2000

[15] CABRNOCH, B., KRÁL, M. (2012). Predbéžná analýza kompozitového čela vlaku, VZLÚ, Praha, 2012

[16] HREN, I., MICHNA, Š., CAIS, J., MICHNOVÁ, L. (2020). Research of the influence of impurities on the occurrence of intermetallic phases in AlMg3 alloy. Manufacturing Technology, Vol. 20, No. 3, pp. 318-326. ISSN 1213-2489.

[17] HREN, I., LUNAK, M., KUSMIERCZAK, S. (2020). The formation and elimination of the negative influence of porosity on the properties of the alloy castings AlSi10Mg. Manufacturing Technology, Vol. 20, No. 2, pp. 170-176. ISSN 1213-2489. 